\title{
Chemometrics Optimization of Volatile Organic Compounds Analysis in Water by Static Headspace Gas Chromatography Mass Spectrometry
} Mohammad Hossein Fatemi*, Hossein Kouchakpour and Hanieh Malekzadeh

Laboratory of Chemometrics, Faculty of Chemistry, University of Mazandaran, Babolsar, Iran

\begin{abstract}
Static headspace coupled with gas chromatography-mass spectrometry was applied to extraction and analysis of volatile organic compounds in water samples. The effects of various factors affecting on the extraction efficiency including: the extraction temperature, extraction time, salt concentration and stirring speed were carried out by means of a $2^{4}$ full factorial design. It was found that the effects of extraction temperature and salt concentration were significant. Then, a central composite design was performed to optimize the level of these factors. The optimal headspace conditions were achieved when the vials were heated under $88^{\circ} \mathrm{C}$ and $29 \% \mathrm{w} / \mathrm{w}$ addition of salt. At optimum operating conditions, analytical figures of merit of method such as linearity (0.9962-0.9996), repeatability $(1.2-12.13 \%)$, detection limits $\left(0.1-4.9 \mu \mathrm{g} . \mathrm{L}^{-1}\right)$ and linearity dynamic range $\left(10-1000 \mu \mathrm{g} \cdot \mathrm{L}^{-1}\right)$ were determined. The proposed methods can be used to direct investigation of the presence of Volatile organic compounds in environmental samples without pre-treatment of samples. Finally the optimized method was used to investigate the existence of volatile organic compounds in Babolroud River in the north of Iran.
\end{abstract}

Keywords: Optimization; Volatile organic compounds; Static headspace; Experimental design

\section{Introduction}

Volatile organic compounds (VOCs) represent a class of organic substances characterized mainly by high volatility under environmental conditions. The main subgroups of these priority pollutants are halogenated volatile organic compounds (HVOCs), chlorinated shortchain hydrocarbons (CHCs) and monocyclic aromatic hydrocarbons (MAHs) [1,2]. Benzene, toluene, ethyl benzene and xylene (BTEX) are widespread pollutants of which the main source in the outside environment is vehicle traffic and indoor the cigarette smoke. They are also present in small quantities in drinking water and food, in painting substances or adhesives [3].

The main anthropogenic sources of VOCs to aquatic environments are the effluents of urban and industrial activities, including wastewater, atmospheric deposition, urban and rural runoff, extraction accidents, transport and/or transformations of fossil fuels, and natural sources (petrogenic and biogenic) [1,2]. The main reason for assessing VOCs in aquatic environments is their neurotoxic and carcinogenic effects (Huybrechts et al., 2005) [2]. Because of their toxicity, some VOCs have been included in the US Environmental Protection Agency (EPA) list of priority pollutants [4-6]. Also the European Union (EU) has classified several VOCs as priority contaminants (E.U. Directive 2004/42/CE) [7].

There are many reports about determination VOCs in environmental samples. For example, Safarova et al. [8] used headspace analysis combined with gas chromatography mass spectrometry for the analysis of 53 volatile organic compounds in river waters, waste waters and treated water samples down to $0.1 \mu \mathrm{g} . \mathrm{L}^{-1}$ concentration levels. They concluded that the content of VOCs in river water mainly correlates to the content of these compounds in waste waters, which shows the anthropogenic character of the pollutions. Schmidt et al. applied HS-SPME with a Combi-PAL auto sampler to the pre-concentration of waters to obtain good reproducibility. Their method had samplerecovery values of $105-110 \%$ with good sensitivity and reproducibility [9]. For the quantitative work, the methods were validated and showed good linearity, precision, accuracy and limit of detection
(LOD) for the compounds studied. Sample preparation may largely influence the sensitivity and accuracy of measurements of VOCs due to their physico-chemical properties. Several sample introduction modules were coupled to chromatographic systems to improve the measurement quality (e.g., headspace sampling, solid phase micro extraction, purge and trap) $[9,10]$. Headspace analysis is a technique that separate and collect volatile compounds (in the gas phase) from different sample matrices such as water, solids, and foods $[11,12]$. Static or dynamic headspace gas chromatography (GC) analysis is the most adopted methods used by environmental agencies to determine VOCs from solid and liquid matrices [13]. However, direct aqueous injection (DAI) [14], liquid-liquid extraction (LLE) [14], membrane techniques, solid-phase extraction (SPE), solid-phase micro extraction (SPME) $[8,15]$ and distillation techniques are also used as sample preparation techniques in analysis of VOCs. A primary benefit of using headspace GC is that one can analyze small amounts of analytes buried in a large amount of matrix without having to inject the matrix into the chromatography column. This technique results in clean, easy sample preparation coupled with less wear on the chromatography columns and the GC instrument. The static headspace (SHS) technique presents a wide linear dynamic range (with a limit of detection of up to $100 \mathrm{mg} . \mathrm{L}^{-1}$ ) [15], simpler instrumentation $[8,9]$, good repeatability (coefficient of variation 4-10\%) and high recuperation [15-17].

Static headspace is a sampling technique based on physicochemical processes of equilibrium between the solution and the headspace. The success of its use depends on factors such as the chemical nature of the

*Corresponding author: Mohammad Hossein Fatemi, Faculty of Chemistry, Laboratory of Chemometrics, University of Mazandaran, Babolsar, Iran, Tel. +981125242931; Fax: ++9811125342350; E-mail: mhfatemi@umz.ac.ir

Received April 10, 2013; Accepted July 11, 2013; Published July 16, 2013

Citation: Fatemi MH, Kouchakpour H, Malekzadeh H (2013) Chemometrics Optimization of Volatile Organic Compounds Analysis in Water by Static Headspace Gas Chromatography Mass Spectrometry. Hydrol Current Res 4: 153. doi:10.4172/2157-7587.1000153

Copyright: (c) 2013 Fatemi MH, et al. This is an open-access article distributed under the terms of the Creative Commons Attribution License, which permits unrestricted use, distribution, and reproduction in any medium, provided the original author and source are credited. 
Citation: Fatemi MH, Kouchakpour H, Malekzadeh H (2013) Chemometrics Optimization of Volatile Organic Compounds Analysis in Water by Static Headspace Gas Chromatography Mass Spectrometry. Hydrol Current Res 4: 153. doi:10.4172/2157-7587.1000153

Page 2 of 6

compounds to be extracted, the temperature used during extraction, extraction time and amount of added salts [18]. Studies considering the variables one by one to obtain the best possible conditions of SHS sampling have been followed by Gaines et al. [19] and Atchen et al. [20], but these procedures requires a lot of experiments and are also time consuming.

In cases such as this, where many factors influence the response of the system, optimization of the extraction procedure can be carried out using multivariate statistical tools. These provide secure information concerning the best analytical conditions, the existence or otherwise of experimental errors, as well as showing any interactions that might exist between the factors involved. While traditional methods of optimization experiments, where only one variable is analyzed at a time, leaving the others fixed, require a large number of experiments, and do not allow investigating possible interactions between variables, and not explore fully the solution space for optimization [21].

Experimental design, that takes into account simultaneously several variables, seems the most convenient approach searching for the optimal operational conditions in a reasonable number of experiments [22-24]. The principles behind these techniques (known as Design of Experiments (DoE)), encompass the use of experimental design and the generation of mathematical equations and graphic outcomes [24]. Employing various rational combinations of factors, statistical experimental design fits experimental data into mathematical equations (known as models) applied in order to predict and optimize the examined responses. This methodology can be used for optimization of SHS conditions to determine VOCs in water. Examples of GC development and optimization attempts with the aid of DoE have shown important advantages [25-28].

The aim of the present paper was to develop and optimize a static headspace gas chromatography-mass spectroscopy method for the determination of VOCs, using experimental design. The significance of the studied factors was evaluated with the aid of a full factorial design (full FD) whilst the optimum SHS conditions were estimated by a central composite design (CCD) using both a graphical and a mathematical global optimization approach. Finally, the proposed method was tested for linearity, specificity, precision, accuracy and robustness (using experimental design).

\section{Reagents}

The standard compounds benzene (99.9\%), ethyl benzene (99\%), xylene (99\%), naphthalene (GC-grade) were taken from Fluka (Buchs, Switzerland) and toluene (99.9\%) were purchased from Aldrich (Milwaukee, USA). 1,2-Dichlorobenzene (99\%) as internal standards and sodium chloride (extra-pure grade) were purchased from Merck (Darmstadt, Germany). Helium gas was $99.999 \%$ pure and obtained from Sabalan Co. (Iran).

A mixed solution of each individual standard in methanol (250 mg. $\mathrm{L}^{-1}$ ) was prepared as the stock standard solution and kept at $4^{\circ} \mathrm{C}$. Working solutions were prepared by diluting appropriate volumes of the stock solution with distilled water.

\section{Instrumentation}

The chromatographic system used was an Agilent model 7890A gas chromatograph equipped with an Agilent model 5975C mass spectrometric detector. This instrument was coupled with a static headspace auto sampler (PAL System). A PC interfaced to the GC using Chemstation software (Agilent Technologies, USA) was used for data acquisition and processing. The chromatographic separations were carried out on a DB-35MS capillary column (Agilent Technologies, USA), $60 \mathrm{~m} \times 0.25 \mathrm{~mm}$ i.d., $0.25 \mu \mathrm{m}$ d.f., with $0.5 \mu \mathrm{m}$ film thickness. All statistical calculations were carried out using the Design Expert 8 and the Statgraphics 5.1 softwares for Windows.

\section{SHS extraction procedure}

Ten milliliter aliquots of water samples containing target VOCs and appropriate amount of $\mathrm{NaCl}$ were placed in a $22 \mathrm{~mL}$ headspace vials (Supelco, USA). These vials were sealed with rubber septa faced with PTFE (polytetrafluorethylene) and then were constantly stirred by an agitator in a controlled temperature for $5 \mathrm{~min}$ before carrying out the SHS.

\section{Gas chromatography-mass spectrometry analysis}

For chromatographic analysis of VOCs, $500 \mu$ of the headspace vapor in the vials was removed with a gas-tight syringe and then injected immediately to the GC-MS. The carrier gas was helium and adjusted at a constant flow-rate of $1.0 \mathrm{~mL} \cdot \mathrm{min}^{-1}$ and the split ratio was 5:1 Oven program temperature was $40^{\circ} \mathrm{C}$ (hold $2 \mathrm{~min}$ ), rate $7^{\circ} \mathrm{C} / \mathrm{min}$ up to $150^{\circ} \mathrm{C}$ (hold $1 \mathrm{~min}$ ), and then rate $15^{\circ} \mathrm{C} / \mathrm{min}$ raised to $200^{\circ} \mathrm{C}$ (hold $2 \mathrm{~min}$ ). The ionization energy was $70 \mathrm{eV}$, the source and quadrupole temperatures were $230^{\circ} \mathrm{C}$ and $150^{\circ} \mathrm{C}$, respectively. The ionization mode was positive ionization. The mass spectra of the sample constituents were compared with a spectra library (Wiley) compatible with chemical classes of the components under study.

\section{Sampling}

The samples were obtained from Babolroud River in the Babolsar city in the northern of Iran. Babolroud is one of the major rivers in the northern of Iran. It originates from Alborz Mountain and flows to the north to discharge in the Caspian Sea. The sampling sites on the Babolroud Rivers were established from the areas of intense port activity, and sink of urban runoff and refinery wastes. Surface water samples were collected during a two-day period in November 2011. Samples were collected in 40-120 ml glass vials and in duplicates. Each vial was filled to capacity to avoid any headspace. All the samples were kept at $4^{\circ} \mathrm{C}$ in the dark. VOCs determinations were accomplished in the laboratory less than $12 \mathrm{~h}$ after the sampling.

\section{Results and Discussion}

\section{Screening design}

Factors that can affect the extraction efficiency of SHS were; extraction temperature, sample salt concentration, stirring speed and extraction time. The particular value for a factor at which an experiment is run is called factor level. The levels of these factors were chosen based on previous experiments [9-12,28]. These factors and their levels are shown in Table 1. A $2^{4}$ factorial design was applied to evaluate the main effects of these factors. The obtained design matrix is shown in Table S1 (of supplementary material). The proposed 16 experiments were run in random manner to minimize the effect of uncontrolled variables. The sum of chromatographic peak areas in analyzing of BTEX samples were considered as experimental response. Then the analysis of variance (ANOVA) was performed on the results by using the Design Expert 8 software to calculate the values of effects and interactions of factors. The results of ANOVA are shown in Table 2. A p-value less than 0.05 in the ANOVA table indicate the statistical significance of an effect at 95\% confidence level. As can be seen in this table, the most significant variables are: extraction temperature $(\mathrm{T})$ and amount of 


\begin{tabular}{|c|c|c|c|}
\hline \multirow{2}{*}{ Factor } & \multirow{2}{*}{ Factor notation } & \multicolumn{2}{|c|}{ Levels } \\
\cline { 2 - 4 } & & -1 & +1 \\
\hline Sample temperature $\left({ }^{\circ} \mathrm{C}\right)$ & $\mathrm{T}$ & 40 & 80 \\
\hline $\mathrm{NaCl}$ in sample $(\mathrm{w} / \mathrm{w}, \%)$ & $\mathrm{S}$ & 5 & 29 \\
\hline Extraction time $(\mathrm{min})$ & $\mathrm{t}$ & 5 & 15 \\
\hline Stirring speed $(\mathrm{rpm})$ & $\mathrm{V}$ & 350 & 650 \\
\hline
\end{tabular}

Table 1: Factors, factor notations and their levels for the $2^{4}$ full factorial design.

\begin{tabular}{|c|c|c|c|c|c|}
\hline Source & Sum of squares & d.f. $^{\mathrm{a}}$ & Mean squares & F-value $^{\mathrm{b}}$ & p-value $^{\mathrm{p}}$ prob $>\mathrm{F}$ \\
\hline $\mathrm{t}$ & $4.13 \times 10^{15}$ & 1 & $4.13 \times 10^{15}$ & 3.31 & 0.0961 \\
\hline $\mathrm{T}$ & $5.21 \times 10^{16}$ & 1 & $5.21 \times 10^{16}$ & 41.77 & $<0.0001$ \\
\hline $\mathrm{S}$ & $3.58 \times 10^{16}$ & 1 & $3.58 \times 10^{16}$ & 28.70 & 0.0002 \\
\hline $\mathrm{V}$ & $2.98 \times 10^{15}$ & 1 & $2.98 \times 10^{15}$ & 3.61 & 0.1505 \\
\hline $\mathrm{tT}$ & $2.35 \times 10^{15}$ & 1 & $2.35 \times 10^{15}$ & 60.35 & 0.0815 \\
\hline $\mathrm{tS}$ & $3.15 \times 10^{15}$ & 1 & $3.15 \times 10^{15}$ & 80.91 & 0.0705 \\
\hline $\mathrm{tV}$ & $2.31 \times 10^{15}$ & 1 & $2.31 \times 10^{15}$ & 59.24 & 0.0823 \\
\hline $\mathrm{TS}$ & $4.61 \times 10^{13}$ & 1 & $4.61 \times 10^{13}$ & 1.18 & 0.473 \\
\hline TV & $1.85 \times 10^{12}$ & 1 & $1.85 \times 10^{12}$ & 0.05 & 0.8634 \\
\hline SV & $1.09 \times 10^{15}$ & 1 & $1.09 \times 10^{15}$ & 28.09 & 0.1187 \\
\hline tTS & $2.94 \times 10^{15}$ & 1 & $2.94 \times 10^{15}$ & 75.41 & 0.073 \\
\hline tTV & $2.17 \times 10^{14}$ & 1 & $2.17 \times 10^{14}$ & 5.58 & 0.2549 \\
\hline tSV & $1.36 \times 10^{15}$ & 1 & $1.36 \times 10^{15}$ & 34.85 & 0.1068 \\
\hline TSV & $2.31 \times 10^{14}$ & 1 & $2.31 \times 10^{14}$ & 5.93 & 0.2481 \\
\hline Residual & $1.37 \times 10^{16}$ & 11 & $1.25 \times 10^{15}$ & & \\
\hline
\end{tabular}

aDegrees of freedom.

b Test for comparing model variance with residual(error) variance.

${ }^{c}$ Probability of seeing the observed F-value if the null hypothesis is true.

Table 2: The results of analysis of variance for the $2^{4}$ factorial design.

salt in sample solution (S).The extraction time and stirring speed and interactions terms had no significant effect on the response. Important factors can also be detected by plotting the Pareto chart (Figure S1) and normal probability plot (Figure S2). These figures confirm that two main factors are the extraction temperature and the salt concentration. The stirring speed and extraction time had no significant effect on the extraction recovery and was eliminated for further studies.

\section{Optimization design}

In the next step, a rotatable, orthogonal central composite design (CCD) was employed to determine the optimal level for the important factors. In statistics, CCD is an experimental design, useful in response surface methodology, for building a second order (quadratic) model for the response variable without needing to use a complete three-level factorial experiment. This design permitted the response surface to be modeled by fitting a second-order polynomial with the number of experiments equal to $\left(2^{\mathrm{f}}+2 \mathrm{f}+\mathrm{n}\right)$, where $\mathrm{f}$ is the number of factors and $\mathrm{n}$ is the number of center runs. In this study, $\mathrm{f}$ and $\mathrm{n}$ were set at 2 and 5 , respectively, which meant that 13 experiments had to be run, out of which 5 are replicate experiments carried out in the center of the design. Eq. (1) was used to calculate the axial spacing, $a$, for a rotatable and orthogonal CCD design:

$$
a^{2}=\frac{\sqrt{\left(\mathrm{N}_{\mathrm{c}}+\mathrm{N}_{\mathrm{a}}+\mathrm{N}_{0}\right) \mathrm{N}_{\mathrm{c}}}-\mathrm{N}_{\mathrm{c}}}{2}
$$

For a design with f factors, $\mathrm{N}_{\mathrm{c}}, \mathrm{N}_{\mathrm{a}}$ and $\mathrm{N}_{0}$ are the number of factorial points $\left(2^{\mathrm{f}}\right)$, the number of star points $(2 \mathrm{f})$, and the number of runs at the center of design, respectively. Using Eq. (1), the axial spacing of $a$ $= \pm 1.414$ was calculated to satisfy rotatability and orthogonality of the design. The factor levels used in the CCD and the corresponding design matrix and responses are shown in Tables 3 and 4, respectively. The
13 experiments found above were run in a random manner, in order to minimize the effect of uncontrolled variables on the response. The Statgraphics 5.1 software was used to analyze the experimental results. To investigate the effects and interactions terms, the Pareto chart and analysis of variance were applied on the results. Figure S3 shows the Pareto chart of standardized effects for CCD design. To evaluate the effects of factors and their interactions, an ANOVA test was performed on these data. The results of ANOVA test on CCD data are shown in Table S2. Then a response surface model was developed by considering all the responses of CCD experiments. The model with the most reasonable statistics, that is, higher F- and R-values and low standard error was considered as the satisfactory response surface equation. The statistics for linear and a second-order models are listed in Table S3, which indicated that the linear model, with $P$ values less than 0.05 was the best model. This linear model is shown in Eq. (2):

$$
\text { Response }=1.35( \pm 0.29) \times 10^{9}+3.06( \pm 0.38) \times 10^{8}(\mathrm{~T})+1.49( \pm
$$
$0.38) \times 10^{8}(\mathrm{~S})$

$$
\mathrm{r}=0.94 \mathrm{SE}=1.22 \times 10^{8} \mathrm{~F}=41.23
$$

where $\mathrm{r}$ is the correlation coefficient, $\mathrm{SE}$ is the standard errors or residuals and F is the Fisher statistics values. In Eq. (2), the coefficients for salt concentration and extraction temperature are large and positive. This shows that the chromatographic peak areas increase extensively with increasing these variables. The mathematical linear model describing the response surface for the CCD. An analysis of variance table has been constructed to examine whether the model accounts for a significant proportion of the total variance in the data (Table 5). The sum of square due to the factors as a percentage of the total sum of squares is $89.2 \%$, showing that a reasonably large proportion of the variance is explained by the model. The variance ratio of the model mean square to the residual mean square gives a value of 41.23 , which is significant at a probability level of $\mathrm{P}<0.0001$, indicating that the regression model accounts for a reasonable proportion of the variance in the responses.

Figure 1 shows the response surface developed by this model. The maximum response was reached when the temperature was close to $88^{\circ} \mathrm{C}$ and the salt concentration was $29 \%(\mathrm{w} / \mathrm{w})$. The factor levels

\begin{tabular}{|c|c|c|c|c|c|}
\hline \multirow{2}{*}{ Factor notation } & \multicolumn{5}{|c|}{ Levels } \\
\cline { 2 - 6 } & -1.414 & -1 & 0 & 1 & 1.414 \\
\hline $\mathrm{T}\left({ }^{\circ} \mathrm{C}\right)$ & 32 & 40 & 60 & 80 & 88 \\
\hline $\mathrm{S}(\mathrm{w} / \mathrm{w}, \%)$ & 1 & 5 & 15 & 25 & 29 \\
\hline
\end{tabular}

Table 3: Factor levels used in the central composite design.

\begin{tabular}{|c|c|c|c|}
\hline Experimental numbers & $\mathrm{T}$ & $\mathrm{S}$ & Response (a.u) \\
\hline 1 & -1 & -1 & $8.64 \times 10^{8}$ \\
\hline 2 & 1 & -1 & $1.44 \times 10^{9}$ \\
\hline 3 & -1 & 1 & $1.06 \times 10^{9}$ \\
\hline 4 & 1 & 1 & $1.64 \times 10^{9}$ \\
\hline 5 & 1.414 & 0 & $1.82 \times 10^{9}$ \\
\hline 6 & -1.414 & 0 & $9.15 \times 10^{8}$ \\
\hline 7 & 0 & 1.414 & $1.67 \times 10^{9}$ \\
\hline 8 & 0 & -1.414 & $1.11 \times 10^{9}$ \\
\hline 9 & 0 & 0 & $1.27 \times 10^{9}$ \\
\hline 10 & 0 & 0 & $1.24 \times 10^{9}$ \\
\hline 11 & 0 & 0 & $1.38 \times 10^{9}$ \\
\hline 12 & 0 & 0 & $1.53 \times 10^{9}$ \\
\hline 13 & 0 & 0 & $1.28 \times 10^{9}$ \\
\hline
\end{tabular}

Table 4: Design matrix and responses for the central composite design experiments. 


\begin{tabular}{|c|c|c|c|c|c|}
\hline Source & Sum of squares & d.f. & Mean squares & F-value & $\begin{array}{c}p \text {-value } \\
\text { prob }>F\end{array}$ \\
\hline Model & $9.205 \times 10^{17}$ & 2 & $4.603 \times 10^{17}$ & 41.23 & $<0.0001$ \\
\hline$T$ & $7.426 \times 10^{17}$ & 1 & $7.426 \times 10^{17}$ & 66.53 & $<0.0001$ \\
\hline S & $1.779 \times 10^{17}$ & 1 & $1.779 \times 10^{17}$ & 15.94 & 0.0025 \\
\hline Residual & $1.116 \times 10^{17}$ & 10 & $1.116 \times 10^{16}$ & & \\
\hline Lack of Fit & $5.524 \times 10^{16}$ & 6 & $9.207 \times 10^{15}$ & 0.65 & 0.6951 \\
\hline Pure Error & $5.637 \times 10^{16}$ & 4 & $1.409 \times 10^{16}$ & & \\
\hline Total & $1.032 \times 10^{18}$ & 12 & & & \\
\hline
\end{tabular}

aThe variation of the data around the fitted model.

Table 5: The results ofanalysis of variance for obtained model.

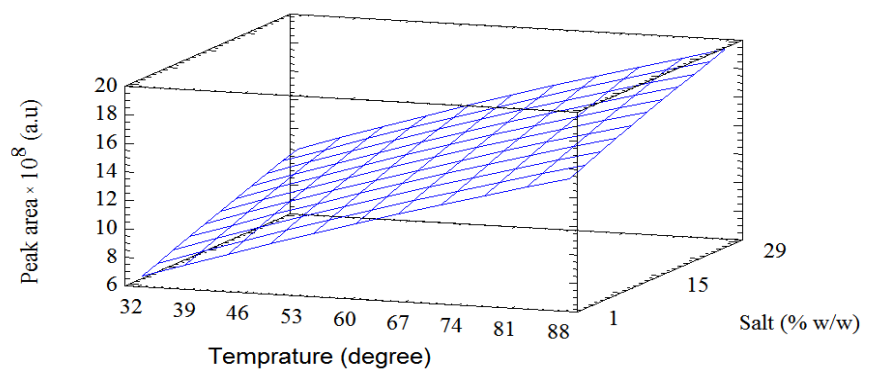

Figure 1: Response surface estimated from the central composite design.

corresponding to the maximum response are considered as optimum conditions. It is interesting to note that the optimum conditions found above were not among the ones chosen during the experiments. In other words, the optimum conditions are not found in the design matrices. At higher temperatures $\left(>90^{\circ} \mathrm{C}\right)$, the vapor pressure of water increases in the headspace vials (gas phase) and decreases the amount of the analytes of interest. In addition, there is a possibility of accidents with the syringe, once the pressure is increased under higher temperatures $[16,29]$. To evaluate the accuracy of improved SHS method, some experiments were carried out under optimum conditions. The results of three replications of experiments in these conditions indicated that, there is a good agreement between the predicted $\left(1.96 \times 10^{9}\right)$ and experimental $\left(1.88 \times 10^{9}\right)$ responses $(95.92 \%)$. The closeness of predicted and experimental responses in optimum conditions reveals the credibility of obtained response surface model.

\section{Real samples analysis}

The calibration curves of VOCs studies were performed at optimum conditions. The resulting calibration curves were linear with mean coefficients of determination $\left(R^{2}\right)$ 0.9988. The limit of detection range was 0.1-4.9 $\mu \mathrm{g} . \mathrm{L}^{-1}$. Table 6 show the statistical parameters including limit of detection, linear range, and relative standard deviation calculated for improved procedure. The percent recoveries of the VOCs used in the present study were measured by spiking $50 \mu \mathrm{g} . \mathrm{L}^{-1}$ of standard VOCs to water samples. The percent of recoveries varied between 88 to $103 \%$. The characteristics performance of this method was compared with other methods in Table 7, which indicated that the detection limits and the linear ranges found in the present work are comparable with the ones found by other researchers who used the SPME [30,31] or SHS [32,33] for analysis.

The optimum SHS conditions were used to analyze of real samples. Figure 2 shows the total ion chromatograms of a Babolroud river water sample. The main organic chemicals in river water were; ethylbenzene

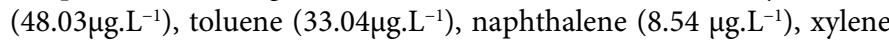
$\left(6.08 \mu \mathrm{g} . \mathrm{L}^{-1}\right)$ and benzene $\left(3.79 \mu \mathrm{g} \cdot \mathrm{L}^{-1}\right)$.
The maximum contaminant level (MCL) of ethyl benzene (700 $\left.\mu \mathrm{g} . \mathrm{L}^{-1}\right)$, toluene $\left(1000 \mu \mathrm{g} . \mathrm{L}^{-1}\right)$, xylene $\left(10000 \mu \mathrm{g} . \mathrm{L}^{-1}\right)$ and benzene $(5$ $\left.\mu \mathrm{g} . \mathrm{L}^{-1}\right)$ is established by EPA [4-6]. Even though the environmental quality standards list comprises naphthalene, maximum permissible limits have not been mentioned for these compounds. The VOC levels found in Babolroud river water samples were lower than the maximum allowable concentration, reported at EPA. Moreover the names,

\begin{tabular}{|c|c|c|c|c|c|}
\hline Analyte & $\begin{array}{c}\text { Regression } \\
\text { equation }\end{array}$ & $\begin{array}{c}\text { Correlation } \\
\text { coefficient } \\
\left(\mathrm{R}^{2}\right)\end{array}$ & $\begin{array}{c}\text { LOD } \\
\left(\mu \mathrm{g} . \mathrm{L}^{-1}\right)\end{array}$ & $\begin{array}{c}\text { Linear range } \\
\left(\mathrm{mg} . \mathrm{L}^{-1}\right)\end{array}$ & $\begin{array}{c}\text { R.S.D. } \\
(\%)(\mathrm{n}=7)\end{array}$ \\
\hline Benzene & $\begin{array}{c}\mathrm{y}=0.0152 \mathrm{x}+ \\
0.0035\end{array}$ & 0.9996 & 0.6 & $0.02-1$ & 12.13 \\
\hline Toluene & $\begin{array}{c}\mathrm{y}=0.0123 \mathrm{x}- \\
0.0694\end{array}$ & 0.9993 & 0.8 & $0.01-1$ & 8.14 \\
\hline Ethyl benzene & $\begin{array}{c}\mathrm{y}=0.0020 \mathrm{x}- \\
0.0051\end{array}$ & 0.9993 & 4.9 & $0.01-0.75$ & 9.56 \\
\hline m/p-Xylene & $\begin{array}{c}\mathrm{y}=0.1312 \mathrm{x}+ \\
0.0742\end{array}$ & 0.9996 & 0.1 & $0.01-0.75$ & 1.20 \\
\hline Naphthalene & $\begin{array}{c}\mathrm{y}=0.0111 \mathrm{x}- \\
0.1268\end{array}$ & 0.9962 & 0.9 & $0.02-0.75$ & 1.47 \\
\hline
\end{tabular}

${ }^{a} y$ is the peak area and $x$ is the analyte concentration in $\mu g \cdot L^{-1}$.

Table 6: Some analytical data obtained for VOCs analysis by SHS-GC-MS.

\begin{tabular}{|c|c|c|c|c|c|c|}
\hline Methods & $\begin{array}{c}\text { Sample/ } \\
\text { Matrix }\end{array}$ & $\begin{array}{c}\text { Limit of } \\
\text { detection } \\
\left(\mu \mathrm{g} . \mathrm{L}^{-1}\right)\end{array}$ & $\begin{array}{c}\text { Linear } \\
\text { range }(\mu \mathrm{g} . \\
\left.\mathrm{L}^{-1}\right)\end{array}$ & R.S.D. (\%) & $\begin{array}{c}\text { Recovery } \\
(\%)\end{array}$ & Ref \\
\hline SHS-GC-MS & $\begin{array}{c}\text { VOCs/river } \\
\text { water }\end{array}$ & $0.1-4.9$ & $10-1000$ & $1.20-12.13$ & $90-108$ & a \\
\hline $\begin{array}{c}\text { SPME-GC- } \\
\text { MS }\end{array}$ & $\begin{array}{c}\text { VOCs/well } \\
\text { water }\end{array}$ & $0.2,03$ & $0.001-1.0$ & $5.4,6.4$ & -- & {$[30]$} \\
\hline $\begin{array}{c}\text { HS-SPME- } \\
\text { GC-FID }\end{array}$ & $\begin{array}{c}\text { VOCs/ } \\
\text { marine } \\
\text { water }\end{array}$ & $1.3-12.8$ & $0.01-5$ & $2.2-5.3$ & $88-103$ & {$[31]$} \\
\hline $\begin{array}{c}\text { SHS-GC- } \\
\text { PID-FID }\end{array}$ & $\begin{array}{c}\text { VOCs/ } \\
\text { seawater }\end{array}$ & $0.22-7.48$ & $0.05-0.5$ & $5.6-9.8$ & --- & {$[32]$} \\
\hline GC- $\mu$ [ECD & $\begin{array}{c}\text { Pesticides/ } \\
\text { soil }\end{array}$ & $0.004-1.2$ & $0.5-200$ & $0.5-14.1$ & $66-147$ & {$[33]$} \\
\hline
\end{tabular}

aThe presence method

'Flame ionization detector

${ }^{\mathrm{c} P h o t o}$ ionization detector

'Micro electron capture detector

Table 7: Comparison of figures of merits and recoveries of the presence method with other works.

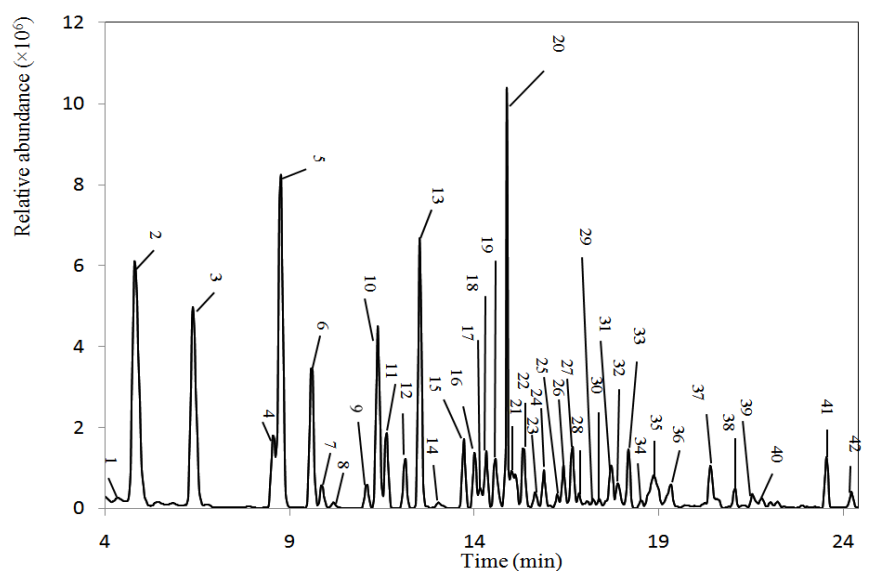

Figure 2: Total ion chromatogram of a river water sample. (experimental conditions are illustrated in the 2.4 section). For peak identities, see Table 8 . 
Citation: Fatemi MH, Kouchakpour H, Malekzadeh H (2013) Chemometrics Optimization of Volatile Organic Compounds Analysis in Water by Static Headspace Gas Chromatography Mass Spectrometry. Hydrol Current Res 4: 153. doi:10.4172/2157-7587.1000153

Page 5 of 6

\begin{tabular}{|c|c|c|c|c|}
\hline number & Compound name & Characteristic ion $(\mathrm{m} / \mathrm{z})$ & Retention time (min) & Relative abundance (\%) \\
\hline 1 & 1-Methyl- cyclopentene & 67 & 4.756 & 0.31 \\
\hline 2 & Benzene & 77 & 5.221 & 13.89 \\
\hline 3 & Toluene & 91 & 6.791 & 9.39 \\
\hline 4 & Ethylbenzene & 91 & 8.972 & 2.31 \\
\hline 5 & $\mathrm{~m} / \mathrm{p}$-Xylene & 91 & 9.164 & 13.49 \\
\hline 6 & o-Xylene & 91 & 10.004 & 5.19 \\
\hline 7 & Styrene & 104 & 10.281 & 0.84 \\
\hline 8 & (1-methylethyl)-benzene & 120 & 10.597 & 0.23 \\
\hline 9 & Propyl benzene & 91 & 11.495 & 0.79 \\
\hline 10 & 1-Ethyl-3-methyl benzene & 120 & 11.799 & 6.30 \\
\hline 11 & 1,3,5-Trimethyl benzene & 105 & 12.031 & 2.43 \\
\hline 12 & 1-Ethyl-2-methyl benzene & 120 & 12.534 & 1.57 \\
\hline 13 & 1,2,3-Trimethyl- benzene & 105 & 12.939 & 8.49 \\
\hline 14 & 1-Methyl-2-(1-methylethyl)- benzene & 119 & 13.44 & 0.29 \\
\hline 15 & 1,2,4-Trimethyl- benzene & 105 & 14.126 & 2.11 \\
\hline 16 & 1-Methyl-3-propyl- benzene & 105 & 14.42 & 1.68 \\
\hline 17 & (1-Methylpropyl)- benzene & 173 & 14.575 & 0.51 \\
\hline 18 & 2-Ethyl-1,4-dimethyl- benzene & 119 & 14.734 & 1.79 \\
\hline 19 & Indane & 117 & 14.979 & 1.83 \\
\hline 20 & 1,4-Dichloro- benzenea & 146 & 15.284 & 2.26 \\
\hline 21 & 2-Ethyl-3,4-dimethyl- benzene & 119 & 15.426 & 1.98 \\
\hline 22 & 2-Ethyl-1,3-Idimethyl- benzene & 119 & 15.745 & 1.95 \\
\hline 23 & 2-Butenyl- benzene & 117 & 16.062 & 0.56 \\
\hline 24 & 1-Ethenyl-3-ethyl- benzene & 117 & 16.295 & 1.21 \\
\hline 25 & 2-Ethyl-1,4-dimethyl- benzene & 119 & 16.661 & 0.39 \\
\hline 26 & 1,2,4,5-Tetramethyl- benzene & 134 & 16.829 & 1.30 \\
\hline 27 & 1,2,3,5-Tetramethyl- benzene & 134 & 17.07 & 1.93 \\
\hline 28 & (1,1-Dimethylpropyl)- benzene & 119 & 17.243 & 0.45 \\
\hline 29 & 1-Methyl-3-(1-methyl-2- propenyl)- benzene & 119 & 17.632 & 0.30 \\
\hline 30 & 2-Ethyl-1,3-dimethyl- benzene & 119 & 17.797 & 0.31 \\
\hline 31 & 1H-Indene, 2,3-dihydro-5-methyl- & 117 & 18.12 & 1.67 \\
\hline 32 & 2-Ethyl-1,3-dimethyl- benzene & 119 & 18.301 & 0.96 \\
\hline 33 & 1-Methyl-4-(1-methylethenyl) benzene & 117 & 18.594 & 1.75 \\
\hline 34 & 1H-Indene, 1-methyl- & 132 & 18.928 & 0.24 \\
\hline 35 & 2,3-dihydro-4,7-dimethyl-1H-Indene & 131 & 19.272 & 2.41 \\
\hline 36 & 1H-Indene, 2,3-dihydro-1,6-dimethyl- & 131 & 19.726 & 1.22 \\
\hline 37 & Naphthalene & 128 & 20.811 & 2.06 \\
\hline 38 & 1H-Indene, 2,3-dihydro-4,7-dimethyl- & 131 & 21.467 & 0.64 \\
\hline 39 & 2-Ethenyl-1,3,5- trimethyl- benzene & 131 & 21.946 & 0.57 \\
\hline 40 & Ethanone, 1-(4-ethylphenyl)- & 133 & 22.191 & 0.40 \\
\hline 41 & Naphthalene, 1-methyl- & 142 & 23.95 & 1.43 \\
\hline 42 & Naphthalene, 2-methyl- & 142 & 24.628 & 0.60 \\
\hline
\end{tabular}

anternal standard

Table 8: Major VOCs identified in Babolroud river water samples.

retention times, characteristics ions and relative abundance of other identified chemicals in river water sample are listed in Table 8.

\section{Conclusion}

In this work, the effect of different factors on the SHS extraction efficiency of VOCs was studied by performing a $2^{4}$ full factorial experimental design. The results showed that the percent of $\mathrm{NaCl}$ in the water samples and the extraction temperature were dominant factors in extraction efficiency of SHS. The results of VOCs analysis in optimum conditions indicated that the analytical figures of merits of the proposed method are comparable with other methods.

The main advantage of proposed protocol is that greatly decreased the risk of contamination or sample loss that can occur in other processes. No potential interferences are introduced, minimizing the problems associated with the sample matrix. The sampling is fast and does not require expensive materials or extensive laboratory work. In addition, it does not use solvents, concentrating samples instead of diluting them, as it often happens when solvent extraction is used.

\section{References}

1. Dewulf J, Van Langenhove H (1997) Chlorinated C1- and C2-hydrocarbons and monocyclic aromatic hydrocarbons in marine waters: An overview on fate processes, sampling, analysis and measurements. Water Res 31: 1825-1838.

2. Huybrechts T, Dewulf J, Van Langenhove H (2005) Priority volatile organic compounds in surface waters of the southern North Sea. Environ Pollut 133: 255-264.

3. Kamal MA, Klein P (2010) Estimation of BTEX in groundwater by using gas chromatography-mass spectrometry. Saudi J Biol Sci 17: 205-208.

4. US EPA (1984) Phenols, Environmental Protection Agency, Washington DC USA. 
Citation: Fatemi MH, Kouchakpour H, Malekzadeh H (2013) Chemometrics Optimization of Volatile Organic Compounds Analysis in Water by Static Headspace Gas Chromatography Mass Spectrometry. Hydrol Current Res 4: 153. doi:10.4172/2157-7587.1000153

5. US EPA (2009) Ground water \& drinking water: national primary drinking water regulations, Environmental Protection Agency, Washington DC, USA.

6. US EPA (1996) Volatile organic compounds by gas chromatography/mass spectrometry, Environmental Protection Agency, Washington DC, USA.

7. Directive 2004/42/CE of the European Parliament and of the Council of 21 April 2004 on the limitation of emissions of volatile organic compounds due to the use of organic solvents in certain paints and varnishes and vehicle refinishing products and amending Directive 1999/13/EC

8. Safarova VI, Sapelnikova SV, Djazhenko EV, Teplova GI, Shajdulina GF, et al. (2004) Gas chromatography-mass spectrometry with headspace for the analysis of volatile organic compounds in waste water. J Chromatogr B Analyt Technol Biomed Life Sci 800: 325-330.

9. Demeestere K, Dewulf J, De Witte B, Van Langenhove H (2007) Sample preparation for the analysis of volatile organic compounds in air and water matrices. J Chromatogr A 1153: 130-144.

10. Schmidt TC, Haderlein SB, Pfister R, Forster R (2004) Occurrence and fate modeling of MTBE and BTEX compounds in a Swiss Lake used as drinking water supply. Water Res 38: 1520-1529.

11. Kolb B (1999) Headspace sampling with capillary columns. J Chromatogr A 842: 163-205

12. Kolb B, Ettre LS (2006) Static Headspace-Gas Chromatography: Theory and Practice. John Wiley \& Sons, Hoboken, New Jersey, USA.

13. US EPA SW-846 (2012) In: Test methods for evaluating solid wastes physical/ chemical methods.

14. Golfinopoulos SK, Lekkas TD, Nikolaou AD (2001) Comparison of methods for determination of volatile organic compounds in drinking water. Chemosphere 45: $275-284$

15. Ketola RA, Virkki VT, Ojala M, Komppa V, Kotiaho T (1997) Comparison of different methods for the determination of volatile organic compounds in water samples. Talanta 44: 373-382.

16. Menéndez JCF, Sánchez MLF, Uría JES, Martínez EF, Sanz-Medel A (2000) Static headspace, solid-phase microextraction and headspace solidphase microextraction for BTEX determination in aqueous samples by gas chromatography. Anal Chim Acta 415: 9-20.

17. Ridgway K, Lalljie SP, Smith RM (2007) Use of in-tube sorptive extraction techniques for determination of benzene, toluene, ethylbenzene and xylenes in soft drinks. J Chromatogr A 1174: 20-26.

18. Nongonierma A, Cayot P, Queacutereacute JLL, Springett M, Voilley A (2006) Mechanisms of extraction of aroma compounds from foods, using adsorbents. Effect of various parameters. Food Rev Int 22: 51-94.

19. Gaines RB, Ledford EB, Stuart JD (1998) Analysis of Water Samples for Trace Levels of Oxygenate and Aromatic Compounds Using Headspace Solid-Phase
Micro extraction and Comprehensive Two-dimensional Gas Chromatography. J Microcol Sep 10: 597-604.

20. Achten C, Kolb A, Püttmann W (2001) Sensitive method for determination of methyl tert-butyl ether (MTBE) in water by use of headspace-SPME/GC-MS. Fresenius J Anal Chem 371: 519-525.

21. Ferreira SL, Bruns RE, da Silva EG, Dos Santos WN, Quintella CM, et al. (2007) Statistical designs and response surface techniques for the optimization of chromatographic systems. J Chromatogr A 1158: 2-14.

22. Araujo PW, Brereton RG (1996) Experimental design I: Screening. Trends Anal Chem 15: 26-31.

23. Araujo PW, Brereton RG (1996) Experimental design II: Optimization. Trends Anal Chem 15: 63-70.

24. Singh B, Kumar R, Ahuja N (2005) Optimizing Drug Delivery Systems Using Systematic "Design of Experiments." Part I: Fundamental Aspects. Crit Rev Ther Drug Carrier Syst 22: 27-105.

25. Wang Y, Harrison M, Clark BJ (2006) Experimental design for a basic mixture on a fluorinated packing. The effect of composition of the mobile phase. $J$ Chromatogr A 1105: 77-86.

26. Wang Y, Harrison M, Clark BJ (2006) Optimising reversed-phase liquid chromatographic separation of an acidic mixture on a monolithic stationary phase with the aid of response surface methodology and experimental design. J Chromatogr A 1105: 199-207.

27. Sivakumar T, Manavalan R, Muralidharan C, Valliappan K (2007) Multi-criteria decision making approach and experimental design as chemometric tools to optimize HPLC separation of domperidone and pantoprazole. J Pharm Biomed Anal 43: 1842-1848.

28. Nemutlu E, Kir S, Ozyuncu O, Beksac MS (2007) Simultaneous Separation and Determination of Seven Quinolones Using HPLC: Analysis of Levofloxacin and Moxifloxacin in Plasma and Amniotic Fluid. Chromatographia 66: 15-24.

29. Serrano A, Gallego M (2004) Direct screening and confirmation of benzene toluene, ethylbenzene and xylenes in water. J Chromatogr A 1045: 181-188.

30. Djozan DJ, Bahar S (2003) Monitoring of Phenol and 4-Chlorophenol in Petrochemical Sewage Using Solid-Phase Microextraction and Capillary Gas Chromatography. Chromatographia 58: 637-642.

31. Bagheri H, Mir A, Babanezhad E (2005) An electropolymerized aniline-based fiber coating for solid phase microextraction of phenols from water. Anal Chim Acta 532: 89-95.

32. Mousavi M, Noroozian E, Jalali-Heravi M, Mollahosseini A (2007) Optimization of solid-phase microextraction of volatile phenols in water by a polyanilinecoated Pt-fiber using experimental design. Anal Chim Acta 581: 71-77.

33. Dong C, Zeng Z, Yang M (2005) Determination of organochlorine pesticides and their derivations in water after HS-SPME using polymethylphenylvinylsiloxanecoated fiber by GC-ECD. Water Res 39: 4204-4210.
Citation: Fatemi MH, Kouchakpour H, Malekzadeh H (2013) Chemometrics Optimization of Volatile Organic Compounds Analysis in Water by Static Headspace Gas Chromatography Mass Spectrometry. Hydrol Current Res 4 153. doi:10.4172/2157-7587.1000153
Submit your next manuscript and get advantages of OMICS Group submissions

Unique features:

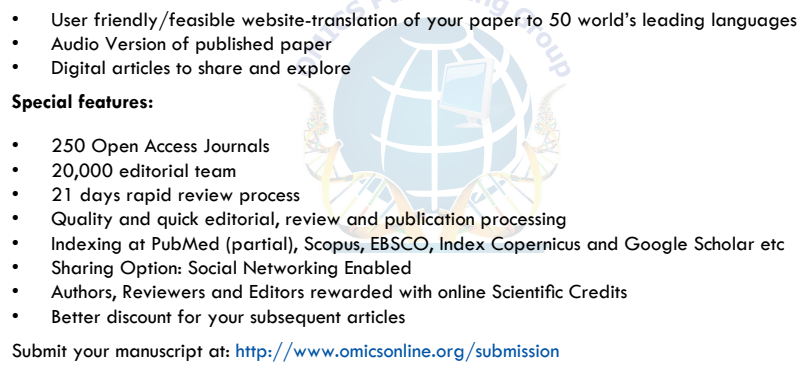

